Theory in Humanitarian Operations Research

Dr Richard Oloruntoba

Newcastle Business School,

The University of Newcastle,

1 University Drive, Callaghan, NSW 2324

Australia

Email: Richard.Oloruntoba@newcastle.edu.au

Ph: +61 249217114

Fax: +612 49216911

Dr Gazi Farid Hossain

Newcastle Business School,

The University of Newcastle,

1 University Drive, Callaghan, NSW 2324

Australia

Email: Gazi.Hossain@uon.edu.au

Dr Beverly Wagner

Department of Marketing

Stenshouse Wing

University of Strathclyde Business School

199, Cathedral Street, Glasgow

United Kingdom G4 0QU

Tel + 441415483246 Fax +44 1415521929

Email: Beverly.Wagner@strath.ac.uk 


\title{
Theory in Humanitarian Operations Research
}

Keywords: Humanitarian Operations; Humanitarian Logistics; Humanitarian Supply Chains; Theory

\begin{abstract}
Academic research on humanitarian operations (HO) is growing (Anaya-Arenas et al. 2014; Burkart et al. 2015; Duhamel et al. 2016). However, attention to and use of relevant theories in associated research is limited (Richey $\mathrm{Jr} 2009$, p.619). Theories are valuable for cultivating a deeper scholarly understanding of a concept such as humanitarian operations. As such, this paper advocates increased deployment of theory in humanitarian operations research. The paper suggests and analyzes 3 social science and management theories as worthy of consideration by scholars and practitioners. The paper generates and stimulates new theory driven research ideas and outlines potential directions for future theoretically rigorous investigations of the practice of operations management in humanitarian contexts.
\end{abstract}


The basic aim of science is theory.

F. P. Kerlinger (1986: 8)

\section{Introduction}

Humanitarian crises and the operational and logistical activities that enable response to them are increasingly common and global in nature (Vega and Roussat, 2015; Day et al 2012). Since the 2004 Asian Tsunami response and the 2005 response to Hurricane Katrina, the world has witnessed several devastating natural and human-made disasters. For instance, the Ebola pandemic in parts of West Africa in 2014, Nepal earthquake in 2015, 2016 Hurricane Matthew in Haiti, and the on-going refugee crisis in Syria, Yemen, north-eastern Nigeria, Iraq and Afghanistan (Yang et al 2015; Kamradt-Scott, 2016; Oloruntoba and Banomyong, 2016).Concomitantly, academic publications on humanitarian operations, logistics and supply chains have grown (Vega and Roussat, 2015; Oloruntoba and Kovacs, 2015; PedrazaMartinez and Van Wassenhove, 2016). However, despite growth in academic publications, attention to and use of academic theories in such areas of research has been limited (Jahre et al 2009; Richey Jr, 2009: 619; Pedraza-Martinez and Van Wassenhove, 2016).

Huffman and Dowdell (2015, p.21) define theory as "a systematic, interrelated set of concepts that explain a body of data." Such interrelated set of concepts is in turn used to explain the nature of phenomena and the relationships between them (Suddaby, 2015; Bacharach, 1989). Sutton and Straw (1995, p.373) pointed out in their seminal work 'what theory is not.' They argued that theory is not a set of literature references, not a set of data and neither is theory a list of variables and/or constructs, or a set of figures, diagrams, hypotheses, or predictions (Sutton and Straw, 1995, p.373, 376, 377).

Also, there is evidence to suggest that manuscripts including humanitarian logistics manuscripts have been rejected by editors in influential management journals in part because there have been a lack of the explicit deployment of theory and insufficient theoretical contribution (Agerfalk, 2014; Horn, 2015; Wright, 2015). Such dearth of use of theory in humanitarian operations research may be as a result of the area of research being practical and applied where practical relevance of research implications for practitioners is of high priority (Tatham and Houghton, 2011; Özdamar and Ertem, 2015; EJOR, 2016:1). Limited development and deployment of theory may also arise out of difficulty in gaining access to 
and difficulty in collecting empirical data in areas that are often remote or in conflict (Wang et al. 2016; Jola-Sanchez et al 2016; Oloruntoba, 2016; Prasad et al. 2016). For such reasons, it is not always possible to develop a theory that is exclusively unique to humanitarian operations (Karatas-Cetin and Denktas-Sakar, 2013). Hence, borrowing and testing theory from other disciplines might represent a theoretical contribution. While developing a theory of humanitarian operations has started receiving some attention (see, e.g., Pedraza-Martinez and Van Wassenhove, 2016; Jola-Sanchez et al 2016), none of the studies focus on borrowing relevant theories from other disciplines and illustrating their usefulness.

To the best of our knowledge, there is no theory published that explicitly addresses humanitarian operations through the lens of internationalization, behavioural and organisational theories. To the best of our knowledge, explicit development and application of these theories for humanitarian operations is non-existent.

Thus in this paper we fill this gap in research by advocating the borrowing and deployment of relevant theory as a compliment to the solid anchoring of humanitarian operations research in empirical reality. Suffice to say that the value of theory in academic research is well discussed and well known (Hambrick, 2007; Hambrick, 2007b; Fawcett and Waller, 2011; Ashkanasy, 2016). In humanitarian operations, theory helps to illuminate complex issues. For example, how best to organize, how to manage logistics, sourcing, strategy, inventory, economics, donor behavior and so forth (Ülkü et al 2015; Muller et al 2014). In addition, the inherent multifaceted nature of humanitarian operations and the environment in which such operations take place calls for the deployment of theories (see Oloruntoba and Kovacs, 2015; Burkart et al 2015; for a full and more recent discussion of developments in these humanitarian activities and processes). Hence, we argue that complex international humanitarian operations are ripe for a range of analyses using a range of theories such as management and organizational theories and other theoretical frameworks. Hence, the objectives of this paper are to:

(1) Suggest 3 categories of social science and management theories that we consider relevant and useful as a starting point for consideration and deployment by scholars in humanitarian operations; and

(2) Analyse one theory from each of the 3 categories of theory suggested with practical illustrations. 
The contribution of this paper is threefold: First, the paper triggers scholarly and practical awareness and interest in the deployment and application of theory in the field of humanitarian logistics, humanitarian operations and humanitarian supply chain research through a practical analysis of 3 theories that can be valuably deployed in research. Second, the paper generates novel ways of thinking about humanitarian operations research by discussing how each of the three theories may be valuably deployed in research while the field is still maturing. The paper does this by examining humanitarian operations within the context of each of the three theories, discussing strategies for extending research in our field and generating innovative insights in interesting ways as well as providing a broad foundation for theorizing about theory in humanitarian operations research while setting the stage for future research that may include theory deployment. To the best of our knowledge no paper has previously made such contribution.

The rest of the paper is structured as follows: In section 2, we suggest and justify the 3 categories of social science and management theory we consider valuable for scholarly consideration. We afterwards analyze each example theory from the three categories of theory that we suggested as a practical illustration. In section 2, we also discuss how our suggested theories can be practically deployed in research while providing vivid illustrations to buttress our argument. Section 3 is the discussion and conclusion. In section 3 we also discuss the managerial implications of deploying the 3 theories in humanitarian operations research and suggest a clear research stream that ties together the key points made in the paper.

\section{Three suggested categories of theory}

In this section, we suggest and introduce three categories of social science and management theory. We afterwards explore and illustrate the subject of humanitarian operations research through the lens of one theory each from the three suggested categories of theory. The 3 categories are: Internationalization (illustrative example theory is internationalization theory); Behavioral (illustrative example theory is social exchange theory); and Organizational economics (illustrative example theory is transaction cost theory).

These theories are well known and well used in the for-profit management literature thus they require little introduction. It is sufficient however to say that these 3 categories of theories may be classified as endogenous or exogenous to an organization, or a combination 
of endogenous and exogenous (Hymer, 1976; Hoskisson et al., 1999).

In the foregoing discussion, we have suggested three categories of theories: internationalization, and selected an illustrative example theory within the category (internationalization theory) (Dunning, 2003); behavioural, and selected an illustrative example theory within the category (social exchange theory) (Ekeh, 1974; Emerson, 1976); and organizational economics transaction cost theory (Williamson, 1975).

$\underline{\text { Justification }}$

First, we aim to capture three theories from those that emphasize environmental influences where incidentally not much academic empirical work has been done in humanitarian operations. For example, empirical / fieldwork work on global and international humanitarian supply chains, intercultural and social contexts of international humanitarian organizations including UN agencies as well as empirical work on procurement and other transactions in the humanitarian context is rare (see for example, Pedraza-Martinez and Van Wassenhove, 2013). Second, we sought to analyze theories that are sufficiently diverse with respect to their founding origins whether endogenous, exogenous, or combined origins as previously discussed.

Third, we suggest well-known organizational theories, each of which views the issue of humanitarian operations through a different lens. This enables us to develop multiple perspectives about what challenges, puzzles, and problems are most pressing and important in humanitarian operations, what humanitarian organizations might do to solve them, and why such challenges arise. Our opinion is that combined insights arising from multiple theoretical perspectives hold the potential of offering a more holistic framework to guide knowledge creation about humanitarian operations management. Fourth and last, we utilize this diversity of thought to lay a conceptual foundation for subsequent theoretically robust explorations of humanitarian operations. We now analyze each example theory.

\section{Internationalization Theory}

Internationalization theory has to do with why some organizations pursue foreign direct investment (FDI) and other organizations do not. Scholars such as Dunning (2003) have 
incorporated various extensions into the basic internationalization decision taken by managers within the organization. The key assumptions are that the costs of doing business abroad results in a competitive disadvantage for a multinational corporation (MNC) or any organization operating overseas as a result of additional costs incurred by the organization (i.e. the liability of foreignness) (Hymer, 1976; Parkhe, 2003). For instance, costs associated with geographic distances in international humanitarian operations increases transportation and distribution costs. Operational and facility location decisions become more complex owing to warehousing cost trade-offs due to increased order cycles and lead times (Meixell and Gargeya, 2005; Santos-Panate, 2016). Extra costs may also arise for humanitarian operations as a result of exposure to different and new languages, customs, values, cultures, and non-Western practices as well as from beneficiary, or host country environment. For example, poor infrastructure, nationalist policies, supplier non-availability, product quality and perceptions of illegitimacy of foreign owned or foreign operated organizations (Asmussen et al, 2009).

Internationalization theory attracts attention to the range of costs and other barriers that must be overcome by humanitarian organizations and their global supply chains. Humanitarian organizations will face costs associated with their unfamiliarity with the local environment (Calhoun, 2002). For example, material planning, scheduling, demand forecasting and needs assessment processes could be diminished as humanitarian practitioners wrestle with exposure to new and different languages, practices and cultures. Costs may also arise from more macro aspects of the recipient country environment, such as nationalism, inferior infrastructure, or low levels of legitimacy for foreign organizations (Asmussen et al. 2009). For instance, Western organizations sometimes need to overcome negative perceptions about them that are deep seated in a recipient country's national memory.

The home country itself may impose costs that influence global humanitarian supply chain decisions (Oloruntoba and Gray, 2003). For instance, there may be restrictions on where to source relief goods and where not to source (Ülkü et al 2015). There are often donor nominated preferred suppliers/countries that have been pre-identified hence markets are distorted (Ülkü et al 2015). There is also the issue of tied aid where specific suppliers from a limited number of specified countries supply pre-specified goods in kind with little regard 
to what is actually needed in a humanitarian crisis (Thomas, 2003). Similarly, there may be home country tax incentives associated with establishing international developmental assistance supply chains in some countries that nullifies open market mechanisms and efficient competitive bidding. As humanitarian organizations focus on reducing logistics and supply chain management costs and overall project costs, internationalization theory draws attention to potentially competing costs that must be overcome if humanitarian organizations are to be efficient and more effective and efficient in their humanitarian endeavors given their accountability to donors (Zaheer, 1995; Ülkü et al 2015).

Internationalization theory brings with it a significant body of knowledge that could considerably inform research on the international experience of top managers of international organizations, prior international alliances and partnerships, and organizational size and structure (Zaheer, 1995; Hitt et al., 2006). Such factors may be important determinants of global procurement and supply chain relationships that could interact with efficiency-based factors to influence partnering decisions (Zaheer, 1995; Hitt et al., 2006). The internationalization perspective also differentiates between the (1) scope and (2) scale of international diversification of a humanitarian organization. Scope describes the range of countries, regions, or people/cultural groups with which a humanitarian supply chain and distribution chain is engaged (Anderson and Coughlan, 1987). Scale describes the extent to which an organization's suppliers and buyers cross national borders (Hitt et al, 1997).

Lastly, internationalization theory offers a valuable set of ideas about how globalizing the humanitarian supply chain could affect overall performance. For instance, after learning about their new / foreign environments and gaining access to knowledge and local cultural expertise; a natural research question is: Are longer-term repetitive humanitarian supply chains such as development or reconstruction supply chains more likely to experience performance gains? If so how? However, would such supply chains encounter a threshold, where the costs of logistical involvement and coordination in several countries exceed the benefits of increased access to knowledge and local/cultural expertise and resources? 


\section{Social exchange theory}

The key tenets of social exchange relate to (1) subjective perceptions of the value of the resources being exchanged, or passed from one party to another (2) obligations and expectations that might often emerge regarding those exchanges of resources, and (3) development and maintenance of often-complex political and social relationships resulting from recurring exchanges (Biggart and Delbridge, 2004; Cropanzano and Mitchell, 2005; Coleman, 1986; Ekeh, 1974; Emerson, 1976). For instance, in the context of rich country donor and poor country recipient relationships in which humanitarian operations involve sourcing and shipment of relief and other valuable goods and services from donor countries to poorer, more vulnerable countries; or outsourcing relief goods and services from within country (Wang et al 2016).

Such tenets align with the (a) exchange of specialized knowledge and other resources between humanitarian organisations and beneficiaries, (b) development of commitment and trust, and (c) inculcation and appreciation of relational norms and organisational competencies by incumbents. For instance managers of foreign humanitarian organisations and their potential successors such as national governments and local partners and NGOs who take over humanitarian projects and associated logistics when projects are completed (Dyck et al 2002; Kamradt-Scott, 2016). There are also other stakeholders such as impacted communities, local public health agencies who are integral to the hand over and succession process.

Social exchange theory allows a discussion of the social structures that define, condition, and constrain succession processes in humanitarian operations while retaining the ability to fully incorporate motives and agency. Succession and handover can also occur within country contexts. For instance after Hurricane Katrina when the City of New Orleans and the State of Louisiana took over on departure of helpers from other states in America (Dyck et al 2002; Kamradt-Scott, 2016).

Turner (2003, p. 322) noted that because actors can be individual persons or collective actors such as groups, organizations, corporations or nations, the micro - macro problem of connecting people to a particular mechanistic organizational structure is obviated when 
addressing complex research issues within a social exchange perspective. Therefore: (1) by employing a social exchange theoretical perspective we integrate current knowledge on succession in a theoretical model relevant to humanitarian operations scholars, and (2) a social exchange perspective offers a conceptual foundation for examining exchange relationships across various groups of actors, governments, specialists, logisticians, public health officials, military, nutritionists, community members and other stakeholders during the various phases of a succession process. Behaviour and sociology scholars have all proposed multiphase models and suggested that the transition phase consists of: three phases (e.g. Cabrera-Suárez et al., 2005; Dyck et al 2002); four phases (e.g. Cadieux et al, 2002; Churchill and Hatten, 1997; Nordqvist et al 2013); or more than four phases (e.g. Chrisman et al, 2009; Sharma et al 2003). However while the number of phases vary, all models align with Le Breton-Miller et al.'s (2004) three-phase seminal model of succession transition.

In Phase 1 of Le Breton-Miller et al.'s (2004) model, rules and criteria are established for the process of handing over (transition) and communicated. Potential successors are then identified and a succession plan created. The skills, abilities and responsibilities of potential successors are assessed, gaps identified and training provided for development in Phase 2. In Phase 3 formal power/authority transfer and handover occurs with the incumbent stepping down and the chosen successor assuming the role of top manager.

Social exchanges may be categorized based on the actors involved in an exchange such as: (a) Exchanges involving entities or stakeholders within or outside the context of exchanges

(b) Other stakeholders, and

(c) Exchanges between successors and incumbents (Ekeh, 1974; Emerson, 1976).

Social exchanges and interactions may occur at daily or weekly meetings, for example, between incumbents (e.g. humanitarian organisations and NGOs) and local stakeholders such as local partners and national governments (Hilhorst, 2003).

While social exchange has often been viewed from a simplified dyadic perspective, in this paper we tend to agree with Biggart and Delbridge (2004) who suggest that actors exist at 
various levels in an exchange system. Interpersonal and inter-organisational ties that result in the development of social capital, social networks and shared identities among exchangegroup members begin one interaction at a time, one individual to another (Hilhorst, 2003). However, with repeated exchanges among members of the group comes an accumulation of obligations, trust and expectations that constitute the exchange patterns which may be similar to those identified in social network theory (Hilhorst, 2003; Biggart and Delbridge, 2004).

Furthermore, in addition to observable network structures, repeated interactions also influence the types and extent of shared schemata which is characterized by common vision, common understanding, common knowledge, and some form of group solidarity and trust. Such shared schemas serve as a frame of reference for future exchanges within members of an exchange group (Granovetter, 1985; Hilhorst, 2003). Over time, these schemas may be passed on to new group members for continuity. Hence, it is the ability of a social exchange perspective to address the big picture of the networks of social interactions in the humanitarian operations context over time and across various levels that leads us to advocate for its utility. The social exchange perspective does serve as an overarching, unifying theoretical architecture that connects extant and future research in humanitarian project transitions, transitioning, succession and handover. This theory can be applied to potential human resource studies of international humanitarian agencies in areas such as expatriation of humanitarian staff, repatriation and domestic geographical relocation, and their adjustment to new job assignments including knowledge transfer between foreign staff. An exchange perspective also provides a ready means to study the mechanics of such relationships and to understand how valuable resources such as knowledge for instance, epidemiological expertise are transferred from foreign responders to local national experts and beneficiaries. Studies on the strategic management and deployment of humanitarian logistics personnel / human resource are rare in the humanitarian operations literature as well as studies that explore or link the human resource policies of humanitarian organizations with their strategic objectives.

Social exchange theory helps to develop new approaches and insights into fundamental succession questions at the end of humanitarian action/projects or at the end of disaster management phases such as emergency relief, reconstruction and rebuilding. Groves (2007) 
argued that a successful and effective succession process depends on the level of understanding and mutual respect between incumbent and successor, grounded in support, trust, communication, and mutual learning. Perceptions of mutual obligation and competence should begin prior to handover. Indeed, Santora et al (2015) noted that the quality of the incumbent-successor relationship is critical to an effective succession. Thus, a social exchange perspective may offer a way to organize succession knowledge in the management of humanitarian operations.

\section{$\underline{\text { 3.Transaction cost }}$}

The total expenses of carrying out an exchange between organizations in the marketplace or a transfer of resources within an individual organization whether or not its branches are in different countries is often referred to as transaction costs (Williamson, 1975, 1981, 1985). Transaction cost economics is premised on the fact that costs created within market and non-market exchanges are influenced by several important variables such as asset specificity (Williamson, 1975, 81); bounded rationality (Williamson, 1975, 81); contract specificity (Williamson, 1975, 81); trust (Whipple et al 2013) and agency (Jensen and Meckling, 1976).

Asset specificity arises when an exchange partner has invested in resources that are of limited or no value in other exchange contexts (Williamson, 1975, 81). Asset specificity is a term related to the inter-party relationships of a transaction. It is usually defined as the extent to which the investments made to support a particular transaction have a higher value to that transaction than they would have if they were redeployed for any other purpose.

There are various forms of asset specificity. These include: (1) Physical-Asset Specificity. For instance, the Ebola specific equipment deployed during the recent Ebola epidemic of 2014 may no longer be of value unless there is another outbreak at which such equipment can be re-used. Thus, in this example, the value of an asset can perish; (2) Site Specificity. Site specificity occurs when investments in productive assets are made in close physical proximity to each other. Geographical proximity of assets for different stages of production reduces inventory, transportation, and sometimes processing costs. For instance, the United Nations humanitarian clusters/depots in Dubai, Nairobi, Brindisi (Italy) are major logistical sites; and (3) Human-Asset Specificity refers to the accumulation of knowledge and expertise that is specific to one partner. For instance as regards exclusive proprietary ownership of nutritional wet feeding of malnourished infants or specialized knowledge of 
the logistics of humanitarian relief by such organizations as Atlas Logistique in France or the Fritz Institute in San Francisco (McGuinness 1994).

Bounded rationality arises when partner organizations do intend to make rational decisions, but limited human information processing and interpretation abilities make complete rationality impossible. This may also relate to cognitive block and cognitive dissonance where there is a tendency for individual managers to seek consistency with their cognitions i.e., biases, beliefs and opinions (Cooper, 2007; Festinger, 1957). Hence, key decisions are often taken under conditions of uncertainty.

Contract specificity explains how exchange partners, who are unable to stipulate all of the potential inputs and outputs of an exchange relationship in advance, rely on explicit contracts to govern the exchange. For example contracts of carriage, warehousing or supply. The transaction cost and organizational economics perspective suggests that organizations make sourcing decisions by combining the factors above to determine the optimal economic merit of each transaction (Hobbs, 1996; Williamson, 2008). However, in a global context, aggregated transaction costs at system level forces an organization to take on a new set of complexities if it is to manage a nexus of sourcing decisions as well as other operations and logistics related decisions.

Bounded rationality is affected also by the context in which decisions are made as rules of the game and rules of governance may not be clearly understood (uncertainty). The rules are also not held constant for example due to different cultures or partners or institutions. Property rights may be less secure and legal systems may operate differently (Williamson, 2008). Therefore, assessing transaction costs across national boundaries involves a host of complications that make the task less predictable and this is important because humanitarian organizations must be seen to be efficient with the use of donor funds and must do more with less (Ülkü et al 2015).

Unforeseen events such as sudden political upheaval in a foreign country may impact humanitarian organizations in several ways and managers with a broad understanding of such global and international complexities and a cosmopolitan view of the world may be in a better position to limit the effects of bounded rationality and more accurately assess cross-border transaction costs. A manager who has worked in or traveled to the 
target countries has a more comprehensive understanding of the peculiarities, costs, and risks of operating in each culture and may be in a better position to evaluate the full extent of transaction costs in each country (Hohenthal et al 2014; Santos-Panate, 2016). The management of local logistics knowledge at disaster sites is an emerging area in international humanitarian logistics literature and knowledge is a fundamental condition for humanitarian organizations to operate efficiently.

Operational relationships often take place in multi-context complex interactions (Hitt et al., 2000). Such interactions demand that partner organizations share tacit knowledge and hard - to - codify assets. Hence, confidence that one's partner organization will cooperate in a trustworthy fashion is essential for operational relationships to succeed (Sinkovics et al., 2011).

However, formal contract-based governance i.e., contract specificity may be reduced as confident positive expectations about a partner's behavior and trust increases (Dyer, 1997; Langfield-Smith and Smith, 2003). However, it is more difficult to develop trust across disparate cultures as individual decision makers may have different conceptualizations of efficiency, time, and deadlines as a function of their different national cultures. In short, cultural differences could lead to poor exchanges that make it difficult for trust to develop.

The agency problem describes how there is potentially divergent interests and information asymmetry between principals and their agents (Zsidisin and Ellram, 2003; Dalton et al., 2007). For example between donors and humanitarian organisations and between humanitarian organizations as buyers of relief goods and others who are vendors of relief goods. As a result of asymmetry in information there may be moral hazard and opportunism on the part of vendors who may make decisions that serve their own interests rather than the interest of the principal (Dalton et al., 2007).

The agency view is valuable for research as a result of significant donor funding required for humanitarian operations (Zsidisin and Ellram, 2003; Ülkü et al 2015). Moreover, the area of donor funding is a neglected area of research in spite of donor funding being an important input into the supply chain as humanitarian organizations are agents of their donors and donors donate taxpayer funds (Ülkü et al 2015). In this context, monitoring costs incurred 
by the principal to ensure the agent is not acting opportunistically are often exacerbated by working in different time zones, geographic distance, and a range of other environmental uncertainties (Parkhe, 2003). Compliance and monitoring costs include administration of various accountability reports such as beneficiary lists that are regularly sent by humanitarian organizations to their donors (Thomas, 2003; Ülkü et al 2015).

Likewise for humanitarian organizations operating in a foreign country, the choice of agents such as truck drivers, warehouse providers and providers of other logistics services exposes humanitarian organizations to the risk of opportunism. Adopting agency theory as a theoretical lens in humanitarian operations helps to focus on how to manage cross-border buyer-supplier relationships and the problems that might arise. As discussed, agency risks and costs are subsumed under transaction costs [organization economics] as well as the steps that humanitarian organizations could take to prevent, manage and mitigate those problems. The transaction cost and organizational economics theoretical tradition may be valuable for scholars working in a global humanitarian context for instance, relationships between trust and controls in contracting between culturally distant organizations. We now turn our attention to discussing how to practically deploy these theories in section 3 .

\section{Discussion and Conclusion}

The three theories described and their relevance to humanitarian operations research is meant to trigger ideas and inspire scholars in our field to consider how they might explore research in humanitarian operations in new ways. Theory development in humanitarian operations is in infancy (Richey Jr, 2009; Oloruntoba and Gray, 2009; Kunz and Reiner 2012). Hence, there is enormous opportunity to build on these initial suggestions as it is our view that each of these three theories could be used as the foundation for empirical investigations of humanitarian operations. Scholars may also explore the theories in different types of humanitarian organizations perhaps based on their supply chain structure or institutional contexts.

\section{Combining theories}

One strategy for scholars to add value to their research would be to combine multiple theoretical perspectives to enhance the possible insights about humanitarian operations. A 
study that combines internationalization theory, organization economics and social exchange theory should be interesting. At the heart of internationalization theory is liability of foreignness which describes costs incurred by humanitarian organizations when they go abroad. How humanitarian organizations might establish potential sourcing relationships in countries with different liabilities of foreignness such as different geographic and cultural distances from the home country or different host country institutional contexts should be interesting. Hens (2012) argued that inclusion and collaboration with local partners and stakeholders in foreign contexts are a necessity as a result of institutional voids, and institutional distance limits transferability of business models from developed-country contexts to developing country contexts. Adding internationalization theory to this formula could help describe how humanitarian organizations might overcome liabilities of foreignness in their global operations. Also, if humanitarian operations are not going well in one country, can this leave open the possibility of leaving in favor of where liabilities are less? Internationalization theory could be used to inform research in this regard.

\section{Contrasting theories}

Although combining theories to yield complementary perspectives should yield fruitful insights, more interesting questions might arise from investigating competing theoretical perspectives. For example, interesting contradictions may arise when concurrently examining the global and international humanitarian supply chain through the frame of transaction-cost and organizational economics and social exchange theory. In organizational economics, global sourcing decisions often follow a prescribed formula, describing a precise point at which humanitarian organizations should engage in contracts to accomplish specific goals. Social exchange theory, however, would suggest that an organization will make social exchanges that align with social, normative, cognitive, and regulative norms, which may not always be the most economically efficient.

In structuring their supply chain relationships, humanitarian organizations might find themselves under competing influences from legitimacy-minded institutions as well as efficiency-minded principals such as donors. Contradictions might arise with the parallel exploration of competitive advantage as humanitarian organizations survive and prosper by outmaneuvering rivals in search of resources. This includes humanitarian organizations that must compete for funding and positive global media coverage and influence. Hence, the 
managers of humanitarian organizations must make global supply chain decisions with a view toward minimizing dependence on others and maximizing their power relative to their competitors. However, on the contrary, as they expand their global and international supply chains outward, they could deliberately increase their dependency on others but at the same time becoming more powerful actors in the network. Hence, scholars may want to investigate such co-evolution as humanitarian organizations develop their global and international supply chains.

\section{Extending theories}

Contrasting or combining theories may serve as a valuable means of advancing knowledge. However, scholars can also contribute by extending theories to bridge gaps that may exist in various areas. For instance, scholars might seek to know how multiple levels or echelons of the humanitarian supply chain could affect a conceptual examination of humanitarian supply chains as well as existing models of humanitarian supply chains. Often, humanitarian supply chains are conceptualized very simply as donors (a type of supplier), suppliers of humanitarian goods to humanitarian organizations and beneficiaries often conceptualized as customers (e.g. Oloruntoba and Gray 2006, 2009; Ülkü et al 2015). One way to investigate how multiple levels or echelons of the humanitarian supply chain could affect a conceptual examination would be to embrace a broader emphasis on the multiple tiers of production (i.e. where value is added in the supply chain) as well as distribution within the supply chain (i.e. to end users / beneficiaries or to extended delivery points).

Many studies in humanitarian supply chains focus on and explain decisions surrounding just one tier or echelon of the humanitarian supply chain (e.g. sourcing) without considering the second- order implications for other tiers within the same supply chain. Another option could be to examine several humanitarian supply chains that pass through a single humanitarian agency or organization. Thus, raising new questions about how a humanitarian organization might manage its portfolio of supply chains and how management decisions about one supply chain might affect others in which the humanitarian organization is engaged.

As scholarly research in humanitarian operations matures, the community of scholars in the 
area may be able to develop more comprehensive and sophisticated understandings of the phenomena through the application of multiple level analyses and perspectives. Another approach to extending theoretical exploration of humanitarian logistics and supply chains may be to conceptualize them as a tool or a means to an end rather than as an end in themselves.

Kovacs and Spens (2007) and Oloruntoba and Gray (2006) outlined the notion of competition for donor funds and positive publicity as well as the notion of competitive advantage amongst large multinational humanitarian organizations. The notion of competition is a paradox as scholars sometimes seem to assume that humanitarian organizations do not 'compete' because they are not for profits. Such an approach of seeing actively strategic and competitive humanitarian organizations demands far more from existing theoretical perspectives (e.g. swift trust proposed by Tatham and Kovacs 2010, agility discussed by Oloruntoba and Gray 2006; Dubey and Gunasekaran, 2016; L'Hermitte et al., 2014; Naim and Gosling, 2011; Balcik and Beamon, 2008). Such a view shifts the emphasis from managerial decisions about a component of the humanitarian supply chain to outcomes from the level of individual humanitarian organizations that might have been affected by the end to end supply chain. Hence, as medium or long term humanitarian supply chains engage one another in competition for example for donor funding across several disparate geographically distributed countries, it becomes more important for theoretical investigations to include how such supply chains interact and how individual humanitarian organizations use them to gain competitive advantage.

We also suggest that theory development in humanitarian supply chain research would benefit from more incisive integration of time (or phase of disaster management) into the studies and relationships of interest. For example, it may be valuable to consider how time might be aggregated at levels beyond the conventional emergency relief, rebuilding, and reconstruction phases such that time or phase becomes more conceptually meaningful rather than simplistically and empirically expedient. For example phases often exist together or overlap. Related to the process of aggregation is how long a particular phase/time lasts in humanitarian response. 
Scholars may also discover greater diversity in the rates of change of phases operating in different institutional and cultural contexts. For instance, Nepal after the 2014 earthquake and Haiti after the 2010 earthquake seem to be stuck somewhere in between the emergency phase and the rebuilding phase. Emergency phase is over but the rebuilding, rehabilitation and resettlement/development phase is yet to begin after more than 2 years in Nepal similar to Haiti. Hence, scholars may need to focus more on discontinuous non-linear change of phase hence the significance of studies on frequency, rhythm, cycles, and interruptions. Whetten (1989) explained how to do this. For comprehensiveness, a developed theory is required to explain when concepts or constructs would be applicable. This limits the hypotheses and/ or propositions generated from conceptual models and non-empirical conceptual papers of which much of the published work in humanitarian logistics and supply chains is based. In the following sub-section, we discuss managerial implications.

\section{$\underline{\text { Managerial implications }}$}

The application of multiple theories to humanitarian operations offers practical managerial insights in addition to theoretical insights. Academic research articles often convey vastly different understandings of the same phenomena based upon the perspective from which the authors investigated it. Each perspective by itself provides important information that contributes to the whole, but is also, by itself, incomplete. By drawing attention to the richness of use of a range of theoretical perspectives and investigating how together they might depict the phenomenon, our article offers a valuable description of the phenomenon that can help humanitarian practitioners to comprehend the many motivations that exist and the many issues that arise in humanitarian operations.

Global attention seems to be shifting toward emerging markets, developing countries and socalled bottom of pyramid countries where many humanitarian crises occur (Walsh, 2015; George, 2015; George at al 2016). Additionally, competition in many spheres and industries has triggered the globalization of demand and supply sources (e.g. George at al 2016; Walsh, 2015; Fawcett and Waller 2015). As humanitarian organizations, their managers and donors move forward with embracing the more inevitable globalization of humanitarian supply chains; leveraging the suggested theories could help practitioners to understand the gaps between what could be and what is at the moment in the management of their operations. 
Important global events have highlighted the increasing requirement that practitioners cannot be content with allowing their humanitarian supply chains to react to events or just go along with events without pre-determined goals and aims. For example, Oloruntoba and Kovacs (2015) highlighted a number of developments in humanitarian practice for instance, the development of Islamic humanitarian organizations and Islamic humanitarianism. They also discussed the development and use of cash relief and the increasing of incorporation of community members into key decisions regarding humanitarian assistance and distribution of humanitarian assistance. Managers who understand and have planned for such developments are better placed to survive and prosper their humanitarian organizations than those who have not sufficiently accounted for evolving and arising complexities in global humanitarian practice. Humanitarian logistics and supply chain management is widely known to be the basis of successful and effective humanitarian assistance (Thomas, 2003; Thomas, 2004; Thomas and Kopczak, 2005). However, theory driven and systematic investigations will be needed to assess the scope and depth to which the theories described in this paper describe future possible options and current practice.

The goal of this paper is to generate preliminary ideas and inspire scholars to consider deploying academic theories in their exploration of the phenomenon of humanitarian logistics in novel ways. Internationalization theory, social exchange and transaction costs and organization economics theories should change the types of research questions we ask in humanitarian logistics, and the way we search for findings. The authors hope that this has been accomplished in a basic way.

Humanitarian logistics is a relatively new field of research (Pedraza-Martinez and Van Wassenhove 2016). The environments in which humanitarian challenges manifest themselves are quite varied. They range from longer-term development contexts to immediate post-disaster relief operations, but also from dealing with epidemics and floods to distributing essential supplies to remote areas in difficult last mile situations. There are many situations where the challenge of humanitarian logistics and the humanitarian response operations that it supports are substantially different from commercial operations. Hence, there is a need to apply, adapt and / or develop new concepts, theory, and intuitive insights. 
Humanitarian operations often occur under highly political environments where the influence governments and militaries cannot be ignored.

Thomas Friedman suggested that a history of the world written in 2025 would likely point to flattening of the globe as the most crucial development of our time (Friedman, 2005). Likewise, other scholars identify massive shifts of both potential markets and available workforce from developed to emerging markets which is placing new demands on supply chain managers (see for instance Walsh, 2015; Fawcett and Waller, 2015; George et al 2016). Many of the rules of the past no longer apply and many Western-centric assumptions also no longer apply as managers who operate globally often in remote areas attempt to navigate institutional and cultural differences, geographic distances, language barriers, political uncertainty, currency exchanges, and multiple time zones in their supply chains. As new rules cultural contexts take shape, and the academic community attempts to make sense of them, we believe that the three theories discussed in this article will provide a potent theoretical foundation for exploring ideas, explaining relationships, and understanding the phenomenon of global and international humanitarian logistics and supply chain management. Most importantly, theory can help us bridge the gap between academics and practitioners in our field (Pedraza-Martinez and Van Wassenhove, 2016) and beyond (Rynes and Bartunek, 2001).

\section{Possible directions forward}

Internationalization theory

Internationalization theory offers a valuable set of research ideas about how globalizing the humanitarian supply chain could affect overall performance. For instance, after learning about their new foreign environments and gaining access to knowledge and local cultural expertise; scholars could consider the question: Are longer-term repetitive humanitarian supply chains such as development or reconstruction supply chains more likely to experience performance gains? Would such supply chains encounter a threshold, where the costs of logistical involvement and coordination in several countries exceed the benefits of increased access to knowledge and local/cultural expertise and resources?

\section{$\underline{\text { Social exchange perspective }}$}

The social exchange perspective does serve as an overarching, unifying theoretical 
architecture that connects extant and future research in humanitarian project transitions, transitioning, succession and handover. Scholars could develop new approaches and insights into fundamental questions of succession at the end of humanitarian action/projects. Researchers might ask (a) what antecedents are necessary and sufficient within a humanitarian organization and a local partner to assure successful and effective exchanges and relationships between the humanitarian organization and its local partner? How do such antecedents develop or are cultivated and how do they influence humanitarian organizational and logistical outcomes in aid receiving countries? In other words, what role does preexisting internal conditions of humanitarian organizations and their partners play in successful partnering and collaboration especially in the area of logistics? (b) What are the processes of reciprocation between a humanitarian organization and its local partners? How do local partner organizations reciprocate the decisions and actions of foreign humanitarian organizations and vice versa? Studies of leader-member logistics groupings and the role that each party plays are important given the multi-actor context of humanitarian operations. Overall, studies of reciprocation processes in social exchanges should add richness to scholarly understanding of leader-member relationships within logistics service provision and humanitarian supply chains.

\section{$\underline{\text { Transaction costs }}$}

The agency view is valuable for studies of opportunism, and how to manage cross-border buyer-supplier relationships and the problems that might arise Scholars may also explore the theories in different types of humanitarian organizations perhaps based on their supply chain structure or institutional contexts. Scholars may undertake studies that describe how humanitarian organizations might overcome liabilities of foreignness in their global operations. Scholars may also focus on contradictions that might arise with the concurrent exploration of competitive advantage in the context of humanitarian organizations and how they out-maneuver rivals in search of resources.

Scholars might also explore multiple levels or echelons of the humanitarian supply chain to further build upon existing simplistic models. They might consider second- order implications for other tiers within the same supply chain. Thus, raising new questions about how a humanitarian organization might manage its portfolio of supply chains and how management decisions about one supply chain might affect others in which the humanitarian 
organization is engaged. Research would benefit from integration of time (or phase of disaster management) into the studies and relationships of interest beyond the conventional phases of emergency relief, rebuilding, and reconstruction such as discontinuous non-linear change of phase hence the significance of studies on frequency, rhythm, cycles, and interruptions.

\section{References}

Ågerfalk, P.J. (2014), Insufficient theoretical contribution: a conclusive rationale for rejection? European Journal of Information Systems, Vol. 23(6), pp.593-599

Ashkanasy, N.M (2016), Why we need theory in the organization sciences. Journal of Organizational Behavior, 37(8), pp.1126-1131

Anaya-Arenas, A.M., Renaud, J. and Ruiz, A. (2014), Relief distribution networks: a systematic review. Annals of Operations Research, 223(1), pp.53-79

Anderson, E. and Coughlan, A. T. (1987), International Market Entry and Expansion via Independent or Integrated Channels of Distribution", Journal of Marketing, Vol. 51, pp. 7182.

Asmussen CG, Pedersen T, Dhanaraj C (2009), Host country environment and subsidiary competence: extending the diamond network model. Journal of International Business

Studies 40(1): 42-57.

Bacharach, S. B (1989), Organizational theories: Some criteria for evaluation.

Academy of Management Review, Vol.14, p.496-515

Balcik, B and Beamon, B.M. (2008), "Facility location in humanitarian relief", International Journal of Logistics Research and Applications, Vol. 11 No. 2, pp. 101-121

Biggart, N. W. and Delbridge, R. (2004), Systems of exchange, Academy of Management Review, Vol. 29, 28-49

Burkart, C., Nolz, P.C. and Gutjahr, W.J. (2015), Modelling beneficiaries' choice in disaster relief logistics, Annals of Operations Research, pp.1-21

Cabrera-Suárez, K. (2005), Leadership transfer and the successor's development in the family firm. Leadership Quarterly, 16 (1), 71-96

Churchill, N. C.and Hatten, K. J. (1997). Non-market-based transfers of wealth and power: A research framework for family businesses. Family Business Review, 10(1), 53-67 
Cropanzano, R. and Mitchell, M. S. (2005). Social exchange theory: An interdisciplinary review. Journal of Management, 31 (6), 874-900.

Cadieux, L., Lorrain, J., \& Hugron, P. (2002), Succession in women-owned businesses: A case study. Family Business Review, 15, 17-30

Chrisman, J. J., Chua, J. H., Sharma, P., \& Yoder, T. R. (2009), Guiding family business succession through the succession process: A step-by-step guide for CPA advisors. CPA Journal, 79, 48-51

Calhoun, M.A. (2002). Unpacking liability of foreignness: identifying culturally driven external and internal sources of liability for the foreign subsidiary. Journal of International Management Vol. 8 (3): 301-321.

Cooper, J. (2007), Cognitive dissonance: 50 years of a classic theory. London: Sage Publications.

Coleman, J (1986), Social theory, social research, and a theory of action, American Journal of Sociology, 91, 1309-1335

Dalton, D.R., Hitt, M.A., Certo, S.T. and Dalton, C.M. (2007), The Fundamental Agency Problem and Its Mitigation: Independence, Equity, and the Market for Corporate Control. The Academy of Management Annals, Vol.1 (1), pp.1-64

Day, J.M., Melnyk, S.A. Larson, P.D., Davis, E.W. and Whybark, D.C (2012), "Humanitarian and disaster relief supply chains: a matter of life and death", Journal of Supply Chain Management, Vol. 48 No. 2, pp. 21-36

Dubey, R. and Gunasekaran, A., (2016), The sustainable humanitarian supply chain design: agility, adaptability and alignment. International Journal of Logistics Research and Applications, 19(1), pp.62-82

Duhamel, C., Santos, A.C., Brasil, D., Châtelet, E. and Birregah, B. (2016), Connecting a population dynamic model with a multi-period location-allocation problem for post-disaster relief operations, Annals of Operations Research, pp.1-21.

Dunning, J.H (2003), Some antecedents of internationalization theory. Journal of International Business Studies Vol. 34(2): 108-115

Dyck, B., Mauws, M., Starke, F. A. and Mischke, G. A. (2002), Passing the baton: The importance of sequence, timing, technique and communication in executive succession. Journal of Business Venturing, 17, 143-162

Dyer J.H. (1997), Effective interfirm collaboration: how firms minimize transaction costs and maximize transaction value. Strategic Management Journal 18(7): 535-556.

EJOR (2016), Proposal Special Issue on OR Applied to Humanitarian Operations, European Journal of Operational Research (EJOR) Call for Papers http://www.journals.elsevier.com/european-journal-of-operational-research/call-forpapers/call-for-papers-or-applied-to-humanitarian-operations (accessed 17/11/16) 
Ekeh, P.P. (1974), Social exchange theory: The two traditions. Harvard University Press, Cambridge, MA

Emerson, R. M. (1976), Social exchange theory. Annual Review of Sociology Vol 2, 335362.

Fawcett, S.E. and Waller, M.A. (2015), Designing the Supply Chain for Success at the Bottom of the Pyramid, Journal of Business Logistics, Vol. 36(3), pp.233-239.

Fawcett, S.E., and Waller, M.A. (2011), Making Sense Out of Chaos: Why Theory is Relevant to Supply Chain Research, Journal of Business Logistics Vol.32, No.1, 1-5.

Festinger, L (1957), A theory of cognitive dissonance. Stanford, CA: Stanford University Press.

Friedman, T. L. (2005). The world is flat: A brief history of the twenty-first century. Farrar, Strauss and Giroux, ISBN - 10:0312425074 New York.

George, G (2015), Expanding Context to Redefine Theories: Africa in Management Research, Management and Organization Review, Vol.11, 5-10 (editorial).

George, G., Corbishley, C., Khayesi, J.N., Haas, M.R. and Tihanyi, L. (2016), Bringing Africa in: Promising Directions for Management Research. Academy of Management Journal, Vol.59 (2), pp.377-393

Granovetter, M. (1985), Economic action and social structure: The problem of embeddedness. American Journal of Sociology, Vol. 91, 481-510.

Groves, K.S. (2007), Integrating leadership development and succession planning best practices. Journal of management development, 26(3), pp.239-260

Hens, L. (2012), Overcoming institutional distance: Expansion to base-of-the-pyramid markets. Journal of Business Research, 65(12), pp.1692-1699

Hilhorst, D (2003), Responding to Disasters: Diversity of Bureaucrats, Technocrats and Local People, International Journal of Mass Emergencies and Disasters Vol. 21 (1), 37-56

Hitt, MA., Tihanyi, L., Miller, T. and Connelly, B.L (2006), International diversification: antecedents, outcomes, and moderators. Journal of Management 32(6): 831-867

Hitt, M.A, Hoskisson, R.E, and Kim, H. (1997), International diversification: effects on innovation and firm performance in product-diversified firms. Academy of Management Journal Vol.40 (4): 767-798.

Hambrick, D (2007), The field of management's devotion to theory: Too much of a good thing? Academy of Management Journal, Vol.50: 1345-1352. 
Hambrick, D.C. (2007b), Upper echelons theory: An update. Academy of Management Review, Vol.32, No.2, pp.334-343

Hobbs J.E. (1996), A transaction cost approach to supply chain management. Supply Chain Management: An International Journal Vol.1 (2): 15-27.

Hohenthal, J., Johanson, J. and Johanson, M. (2014), Network knowledge and businessrelationship value in the foreign market. International Business Review, 23(1), pp.4-19

Horn, S.A. (2015), The social and psychological costs of peer review stress and coping with manuscript rejection. Journal of Management Inquiry, p.1056492615586597

http://jmi.sagepub.com/content/early/2015/05/18/1056492615586597.full.pdf+html (accessed $17 / 8 / 16)$

Hoskisson R.E, Hitt M.A, Wan W.P and Yiu D (1999), Theory and research in strategic management: swings of a pendulum. Journal of Management Vol.25 (3), 417-456.

Huffman, K. and Dowdell, K. (2015) Psychology in action (11th ed.). New York: John Wiley \& Sons.

Hymer, S.H. (1976), The International Operations of National Firms. MIT Press: Cambridge, MA.

Jahre, M., Jensen, L.M. and Listou, T (2009) Theory development in humanitarian logistics: a framework and three cases, Management Research News, Vol. 32(11), pp.1008-1023

Jensen, M. C., \& Meckling, W. H. (1976), Theory of the firm: Managerial behavior, agency costs and ownership structure. Journal of Financial Economics, 3, 305-360

Jola-Sanchez, A.F., Pedraza-Martinez, A.J., Bretthauer, K.M. and Britto, R.A. (2016), Effect of armed conflicts on humanitarian operations: Total factor productivity and efficiency of rural hospitals, Journal of Operations Management Vol. 45, pp.73-85.

Karatas-Cetin, C. and Denktas-Sakar, G. (2013), "Logistics research beyond 2000: theory, method and relevance", Asian Journal of Shipping and Logistics, Vol. 29 No. 2, pp. 125-144

Kamradt-Scott, A. (2016), WHO's to blame? The World Health Organization and the 2014 Ebola outbreak in West Africa, Third World Quarterly, 37(3), 401-418

Kerlinger, F. P. (1986), Foundations of Behavioural Research. New York: Holt,

Kovács, G. and Spens, K. (2007), "Humanitarian logistics in disaster relief operations", International Journal of Physical Distribution and Logistics Management, Vol. 37 No. 2, pp. 99-114

Kunz, N. and Reiner, G. (2012), "A meta-analysis of humanitarian logistics research", Journal of Humanitarian Logistics and Supply Chain Management, Vol. 2 No. 2, pp. 116-147 
Langfield-Smith K, Smith D. (2003), Management control systems and trust in outsourcing relationships. Management Accounting Research 14(3): 281-307.

L'Hermitte, C., Tatham, P.H. and Bowles, M. (2014), "Classifying logistics relevant disasters: conceptual model and empirical investigation”, Journal of Humanitarian Logistics and Supply Chain Management, Vol. 4 No. 2, pp. 155-178.

Le Breton-Miller, I., Miller, D., \& Steier, L. P. (2004), Toward an integrative model of effective FOB succession. Entrepreneurship Theory and Practice, 28, 305-328.

McGuinness, T (1994), Markets and Managerial Hierarchies, In G. Thompson, et al. (Eds.), Markets, Hierarchies and Networks, Sage, London, England, 1994, pp. 66-81.

Meixell M.J, and Gargeya V.B. (2005), Global supply chain design: a literature review and critique. Transportation Research 41(6): 531-550

Muller, A.R., Pfarrer, M.D. and Little, L.M., (2014), A theory of collective empathy in corporate philanthropy decisions. Academy of Management Review, 39(1), pp.1-21

Naim, M.M. and Gosling, J. (2011), “On leanness, agility and leagile supply chains", International Journal of Production Economics, Vol. 131 No. 1, pp. 342-354

Nordqvist, M., Wennberg, K., Bau, M., \& Hellerstedt, K. (2013), An entrepreneurial process perspective on succession in family firms. Small Business Economics, 40 (4), 1087-1122

Oloruntoba, R. and Gray, R (2009), Customer service in emergency relief chains. International Journal of Physical Distribution \& Logistics Management, 39(6), pp.486-505

Oloruntoba, R and Banomyong, R (2016), Call for Papers: Special Issue on Logistics and SCM in the Context of Relief for Refugees and Internally Displaced Persons (IDPs) Journal of Humanitarian Logistics and Supply Chain Management.

Oloruntoba, R. and Kovács, G. (2015), A commentary on agility in humanitarian aid supply chains. Supply Chain Management: An International Journal, 20(6), pp.708-716.

Oloruntoba, R (2016). Boko Haram: Challenges and techniques of distributing aid in security challenged environments. In Supply Chain Management for Humanitarians: Tools for Practice Kogan Page Eds Kovacs, G \& Haavisto, I.

Oloruntoba, R. and Gray, R, (2006), Humanitarian aid: an agile supply chain? Supply Chain Management: An International Journal, 11(2), pp.115-120.

Oloruntoba, R. and Gray, R. (2003), Humanitarian Aid Organisations and Logistics, The Institute of Logistics and Transport, Corby.

Özdamar, L and Ertem, M.A. (2015), Models, solutions and enabling technologies in humanitarian logistics, European Journal of Operational Research, Vol. 244(1), pp.55-65

Parkhe A (2003), Institutional environments, institutional change, and international alliances Journal of International Management Vol.9 (3): 305-316 
Pedraza-Martinez, A J., and Van Wassenhove, L.N (2016), "Empirically grounded research in humanitarian operations management: The way forward." Journal of Operations Management, Vol. 45, No 3, p.1-10

Pedraza-Martinez, A.J. and Van Wassenhove, L.N. (2013), Vehicle replacement in the International Committee of the Red Cross, Production and operations Management, Vol. 22(2), pp.365-376

Prasad, S., Zakaria, R. and Altay, N. (2016), Big data in humanitarian supply chain networks: a resource dependence perspective. Annals of Operations Research, pp.1-31

Richey Jr, G. (2009), “The supply chain crisis and disaster pyramid: A theoretical framework for understanding preparedness and recovery." International Journal of Physical Distribution \& Logistics Management, Vol. 39, No.7, pp.619-628

Rynes, S., Bartunek, J. M., and Daft, R. L. (2001), Across the great divide: knowledge creation and transfer between practitioners and academics. Academy of Management Journal, Vol.44, p.340-356

Santora, J.C., Sarros, J.C., Bozer, G., Esposito, M. and Bassi, A. (2015), Non-profit executive succession planning and organizational sustainability: A preliminary comparative study in Australia, Brazil, Israel, Italy, Russia, and the United States. Journal of Applied Management and Entrepreneurship, 20(4), p.66

Santos-Peñate, D.R (2016), Location analysis. Annals of Operation Research, 246 (1), 1- 3

Sinkovics, R.R., Zagelmeyer, S. and Kusstatscher, V. (2011), Between merger and syndrome: The intermediary role of emotions in four cross-border M\&As. International Business Review, 20(1), pp.27-47

Suddaby, R. (2015), Editor's comments: Why theory? Academy of Management Review, Vol. 4015, No.1, p.1-5

Sutton, R. I. and Staw, B. M. (1995), What theory is not? Administrative Science Quarterly, 40: 371-384.

Sharma, P., Chrisman, J. J. and Chua, J. H. (2003), Succession planning as planned behavior: Some empirical results. Family Business Review, 16, 1-16.

Tatham, P and Houghton, L (2011) "The wicked problem of humanitarian logistics and disaster relief aid", Journal of Humanitarian Logistics and Supply Chain Management, Vol. 1 Iss: 1 , pp. 15 - 31

Tatham, P. and Kovács, G. (2010), The application of "swift trust" to humanitarian logistics. International Journal of Production Economics, 126(1), pp.35-45

Thomas, A and Kopczak, L. (2005), From Logistics to Supply Chain Management -The path forward to the humanitarian sector, Fritz Institute, San Francisco. 
Thomas, A. (2003), Humanitarian Logistics: Enabling Disaster Response, Fritz Institute, San Francisco. http://www.fritzinstitute.org/pdfs/whitepaper/enablingdisasterresponse.pdf $(17 / 11 / 16)$

Thomas, A. (2004), Elevating humanitarian logistics, International Aid \& Trade Review, pp. 102-106 http://www.fritzinstitute.org/PDFs/InTheNews/2004/AidandTrade_0104.pdf (accessed 25/11/16)

Turner, J. (2003), The structure of sociological theory. Belmont, CA: Wadsworth

Ülkü, M.A., Bell, K.M. and Wilson, S.G. (2015), Modelling the impact of donor behavior on humanitarian aid operations. Annals of Operations Research, 230(1), pp.153-168

Vega, D. and Roussat, C. (2015), Humanitarian logistics: the role of logistics service providers. International Journal of Physical Distribution \& Logistics Management, 45(4), pp.352-375

Walsh, J.P. (2015), Organization and Management Scholarship in and for Africa... and the World The Academy of Management Perspectives, 29(1), pp.1-6

Wang, X., Wu, Y., Liang, L. and Huang, Z. (2016), Service outsourcing and disaster response methods in a relief supply chain. Annals of Operations Research, 240 (2), pp.471487

Whetten, D. A. (1989), What constitutes a theoretical contribution? Academy of Management Review, 14: 490-495.

Whipple, J.M., Griffis, S.E. and Daugherty, P.J. (2013), Conceptualizations of Trust: Can We Trust Them?. Journal of Business Logistics, 34(2), pp.117-130

Wright, PM (2015), Rethinking “Contribution”, Journal of Management Vol. 41 No. 3, 765768.

Williamson, O. E (1975), Markets and Hierarchies: Analysis and Antitrust Implications. Free Press, New York, NY.

Williamson, O. E (1985), The Economic Institutions of Capitalism, Free Press, New York, NY, 1985.

Williamson, O. E (1981), The Economics of Organization: the Transaction Cost Approach, American Journal of Sociology Vol. 87 (3), November 1981, pp. 548-575.

Williamson O.E. (2008), Outsourcing: Transaction Cost Economics and Supply Chain Management. Journal of Supply Chain Management Vol. 44(2): 5-16.

Yang, F., Yuan, Q., Du, S. and Liang, L. (2015), Reserving relief supplies for earthquake: a multi-attribute decision making of China Red Cross. Annals of Operations Research, pp.1-27 
Zaheer, S (1995), Overcoming the liability of foreignness, Academy of Management Journal Vol. 38 (2): 341-363.

Zsidisin, G. and Ellram, L. (2003), “An agency theory investigation of supply risk management”, Journal of Supply Chain Management, Vol. 39 No. 3, pp. 15-27 